\title{
DEEP-DRAWING AND FATIGUE PROPERTIES OF ADVANCED STEEL SHEET STRIPES
}

Analysis of the deep drawing and fatigue properties is given in this contribution for two advanced micro alloyed sheet steel grades with Yield strength values $R_{e}=246$ and $382 \mathrm{MPa}$, respectively. The $2 \mathrm{~mm}$ thick steel sheets were hot dip zinc coated. The deep drawing properties were evaluated by tensile testing and by the Erichsen test at different strain rates. For fatigue testing the symmetric bending test was applied. Results showed favorable deep drawing properties of these steel sheets assigned for heavy duty parts in automotive industry. Steel grade with $R_{e}=246 \mathrm{MPa}$ had elongation $A_{80}>32 \%, n=0.21$, Erichsen number $I_{E}=12.5 \mathrm{~mm}$ and the steel with $R_{e}=382 \mathrm{MPa}$ had $A_{80}$ $>24 \%, n=0.17$ and $I_{E}=12.4 \mathrm{~mm}$. The tested values showed some growth in dependence on the strain rate up to the press tool velocity about $0.1 \mathrm{~m} \cdot \mathrm{s}^{-1}$ and at higher strain rates they decreased. The fatigue limit in bending was about 0.6.R $R_{e}$. The zinc coating on the sheet surface remains complete up to the final fracture of the test piece.

\section{Introduction}

Zinc coated deep-drawing sheet is marketable in many industrial applications including first of all automotive industry. The barrier effect of zinc protects steel against corrosion in several environments [1, 2]. A light weight design, required mainly nowadays, is possible only with the application of higher strength steel, with maintained plastic properties, the latter essential for steel used in automotive industry. It can be obtained by the use of micro alloyed steel sheet, with micro alloying (under $<0.15 \%$ ) applied together with controlled cooling rolling (thermo-mechanical treatment). For the increase of strength, grain refinement and precipitation strengthening is used. The grain refinement has a beneficial effect on plastic properties too, and it can offset the adverse effect of precipitation hardening [3, 4, 5]. Micro alloyed steel sheet has finer grain than usual steel sheet and that is why the criteria for plastic formability of the sheet are to be modified.

In this contribution the deep-drawing and fatigue properties of selected zinc coated steel sheet are analyzed. The increase of productivity in current press lines is sought in the increase of the pressing speed at first. It means the increase of the strain rate. Higher strain rate results higher resistance of the material to plastic deformation, and changes in the deformation process of the material $[5,6,7]$. As references show, up to a certain value of the strain rate the plastic deformation properties of the material do not change significantly, or the plasticity can even grow slightly [7,8]. The intensity by which the strain rate can influence the plastic properties is strongly material dependent $[4,5]$.

The critical degradation mechanisms influencing the life of an automobile part are the fatigue and corrosion. Cyclic loading is frequently the main factor of surface damage and, on the other hand, surface damages can decrease fatigue properties significantly.

The aim of this contribution is the analysis of plasticity for selected deep drawing zinc coated micro alloyed steel sheet and the evaluation of the influence of strain rate on the analyzed properties, as well as to determine the fatigue properties and to monitor the behavior of the zinc layer during forming and fatigue life.

\section{Experimental material and methods}

Experimental test pieces were made from $2 \mathrm{~mm}$ thick stripes made of micro alloyed cold rolled steel which was hot zinc coated after rolling. The steel was grade $\mathrm{H} 220 \mathrm{YD}(\mathrm{C}<0.01 \%, \mathrm{Al}>0.01 \%$, $\mathrm{Ti}<0.012 \%, \mathrm{Nb}<0.022 \%)$ and H380LAD $(\mathrm{C}<0.15 \%, \mathrm{Al}<$ $<0.01 \%$, Ti $<0.015 \%, \mathrm{Nb}<0.09 \%)$. The grade $\mathrm{H} 220 \mathrm{YD}$ has actually a ferritic microstructure with the mean grain size of 0.016 $\mathrm{mm}$ (Fig. 1) and the grade H380LAD has ferrite with the mean grain size of $0.0056 \mathrm{~mm}$ with a small amount of pearlite (Fig. 2). Cut outs were made from the sheet and flat test pieces oriented in the direction of rolling were machined for tensile testing. The same was applied for the deep drawing Erichsen tests and fatigue tests in bending.

For static tensile tests a universal test machine INSTRON 1185 was used and this machine was used retooled with an Erichsen test fixture for the deep drawing tests in the press tool velocity interval from $3.3 \cdot 10^{-3} \mathrm{~m} \cdot \mathrm{s}^{-1}$ to $1.10^{-3} \mathrm{~m} \cdot \mathrm{s}^{-1}$. Deep drawing tests with ram speed of up to $2.5 \mathrm{~m} \cdot \mathrm{s}^{-1}$ were made in a drop weight tester. The fatigue properties of the steel sheet were tested in bending with symmetrical fatigue cycles at $35 \mathrm{~Hz}$ for the limit $N_{C}=10^{7}$.

\footnotetext{
* Marian Bursak, Jan Michel

Department of Material Science, Technical University of Kosice, Slovakia, E-mail: marian.bursak @tuke.sk
} 


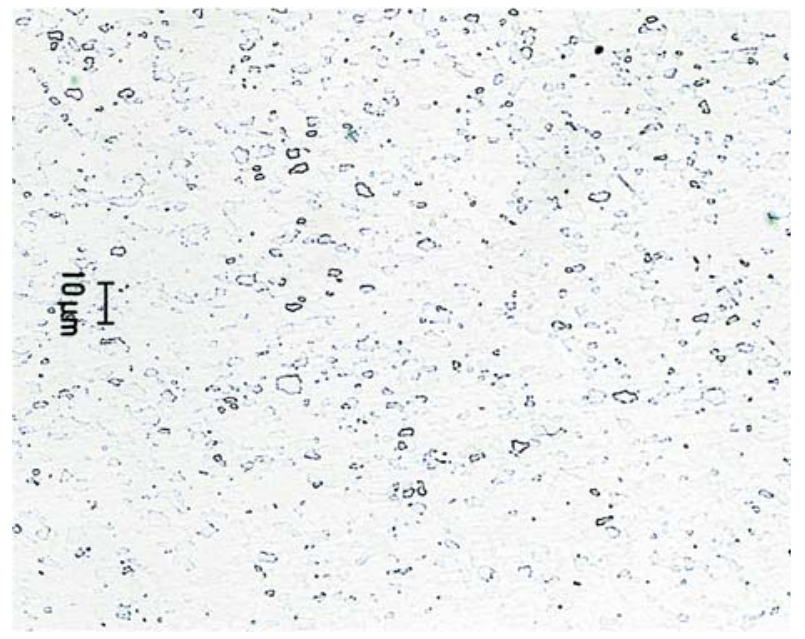

Fig. 1 Microstructure of steel sheet H220YD

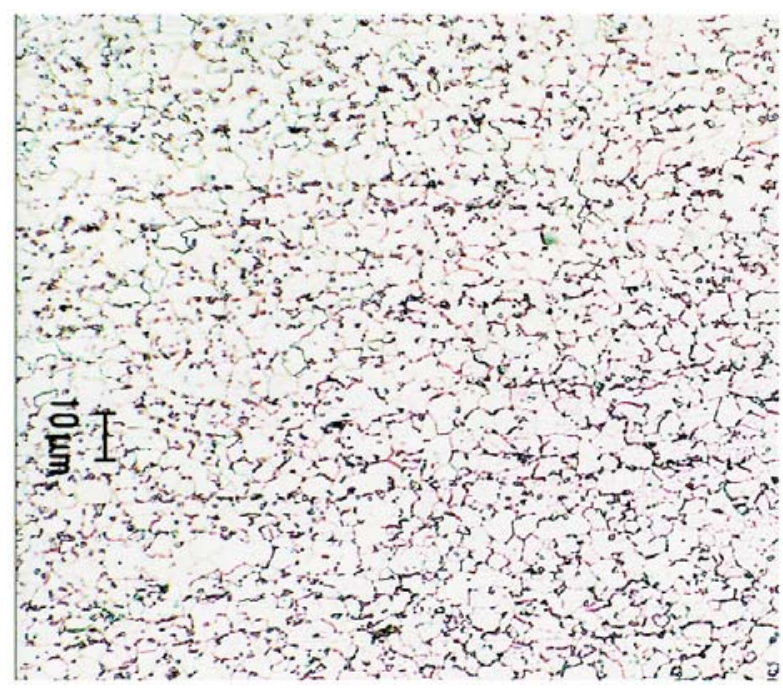

Fig. 2 Microstructure of steel sheet H380LAD

The behavior and integrity of the zinc coating layer was monitored in both macro and microscope.

\section{Results and discussion} Tab. 1.

The tensile test results for the tested $2 \mathrm{~mm}$ thick sheet are in

Mechanical properties of steel sheet

Tab. 1.

\begin{tabular}{|c|c|c|c|c|c|c|}
\hline Steel Grade & $\begin{array}{c}\mathrm{R}_{\mathrm{p} 0,2} \\
{[\mathrm{MPa}]}\end{array}$ & $\begin{array}{c}\mathrm{R}_{\mathrm{m}} \\
{[\mathrm{MPa}]}\end{array}$ & $\begin{array}{c}\mathrm{A}_{80} \\
{[\%]}\end{array}$ & $\mathrm{n}$ & $\mathrm{R}_{\mathrm{p} 0,2} / \mathrm{R}_{\mathrm{m}}$ & $\begin{array}{c}\mathrm{D} \\
{[\mathrm{MPa}]}\end{array}$ \\
\hline H220YD & 246 & 371 & 32.7 & 0.21 & 0.66 & 3590 \\
H380LAD & 382 & 509 & 24.1 & 0.17 & 0.75 & 5050 \\
\hline
\end{tabular}

As shown in Tab. 1 the steel grade with higher strength $(\mathrm{H} 380 \mathrm{LAD})$ has the measured plasticity values lower $\left(\mathrm{A}_{80}, \mathrm{n}\right)$ compared to the steel grade H220YD. The increased strength of steel grade H380LAD in comparison to grade H220YD is first achieved by the finer grain and precipitation strengthening due to the higher carbon content and micro alloying elements. According to the elongation values $\mathrm{A}_{80}$, deformation strengthening exponent $n$, and the ratio $R_{p 0,2} / R_{m}$ the steel grade $H 220$ YD sheet belongs into the group of deep drawing sheet, suitable for deep drawing. Steel grade H380LAD sheet cannot be put into this group for the obtained characteristic values. During plastic deformation for the steel grade H380LAD sheet a higher strengthening modulus D was obtained, tested for the $10 \%$ part of the total deformation.

Basic information about the formability of the steel sheet can be obtained by tensile testing. However, the formability of the sheet is influenced by a number of factors arising from the production technology applied $[7,9,10]$. Important characteristics of formability can be obtained by technological tests. Tab. 2 presents the results of deep drawing Erichsen tests $\left(\mathrm{I}_{\mathrm{E}}-\right.$ is the Erichsen number) at different press tool velocities.

Erichsen deep drawing test results for

Tab. 2. different press tool velocities $\mathrm{v}$

\begin{tabular}{|c|c|c|c|c|c|c|}
\hline Steel Grade & $v\left[\mathrm{~m} . \mathrm{s}^{-1}\right]$ & $3.3 .10^{-3}$ & $8.34 .10^{-3}$ & $1.6 .10^{-2}$ & $2.10^{-1}$ & 2.5 \\
\hline H220YD & $\mathrm{I}_{\mathrm{E}}[\mathrm{mm}]$ & 12.5 & 12.6 & 13.0 & 12.7 & 11.2 \\
\hline H380LAD & & 12.4 & 12.5 & 12.6 & 12.5 & 11.5 \\
\hline
\end{tabular}

Erichsen deep drawing test results showed that the indentation depth up to the fracture of the indented cup $\left(\mathrm{I}_{\mathrm{E}}\right)$ is actually the same for both steel grades used, though they have large differences in elongation $A_{80}$. This can be caused due to difference in the stress distribution at the Erichsen deep drawing test and during tensile test.

The influence of the strain rate on the $\mathrm{I}_{\mathrm{E}}$ values is plotted in Fig. 3. As it can be seen, for the increase of the press tool velocity up to about $v=0.2 \mathrm{~m} \cdot \mathrm{s}^{-1}$ there is a slight growth of the $\mathrm{I}_{\mathrm{E}}$, then there is a slight decrease of the $\mathrm{I}_{\mathrm{E}}$ value. For the highest velocity $2.5 \mathrm{~m} . \mathrm{s}^{-1}$ the obtained value $\mathrm{I}_{\mathrm{E}}$ is the lowest. The turning point velocity $0.2 \mathrm{~m} . \mathrm{s}^{-1}$ marking the start of the $\mathrm{I}_{\mathrm{E}}$ value decrease is roughly equivalent to the strain rate $1 \mathrm{~s}^{-1}$. The experiments are in good agreement with data reported in references $[6,7,8]$, declaring that up to the strain rate of about $1 \mathrm{~s}^{-1}$ there is no significant decrease of steel sheet formability by the increase of the press tool velocity, and in this zone the traditional deep drawing criteria can be applied.

During testing and production by forming due to the heterogeneity of deformation the instant strain rate of a local spot is changing and can be different from the mean value calculated and can be significantly higher. The homogeneity of the plastic deformation is dependent on the microstructure of the steel sheet and 
on the applied forming technology $[4,5]$. The critical forming velocity depends on these factors, too.

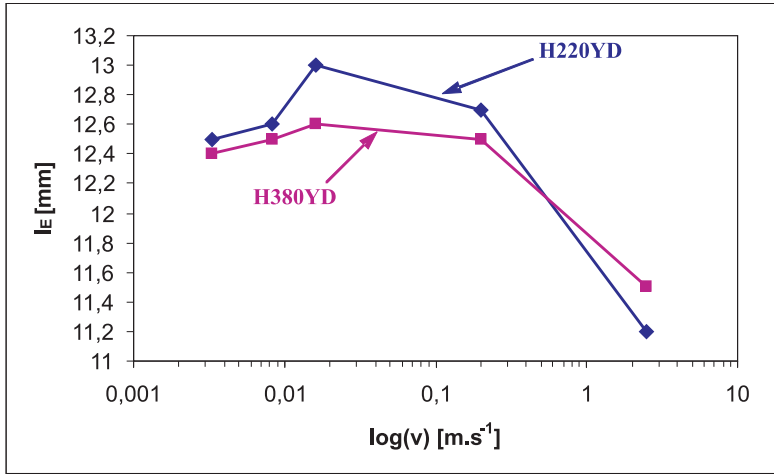

Fig. 3 Influence of pressing tool velocity on Erichsen number $I_{E}$ for investigated steel

The susceptibility of the material to influences caused by strain rate depends on the internal composition of the material. In generally, the higher homogeneity of the internal structure and the lower amount of barriers to the movement of dislocations causes that material is more sensitive to strain rate $[4,5]$. Deep drawing test results show, too, as shown in Fig. 3 that the $\mathrm{I}_{\mathrm{E}}$ value for steel grade H380LAD sheet $\left(\mathrm{R}_{\mathrm{e}}=382 \mathrm{MPa}\right)$ is less susceptible to strain rate than steel grade $\mathrm{H} 220 \mathrm{YD}$ sheet $\left(\mathrm{R}_{\mathrm{e}}=246 \mathrm{MPa}\right)$.

The outstanding decrease of the $\mathrm{I}_{\mathrm{E}}$ at impact forming ( $\mathrm{v}=$ $=2.5 \mathrm{~m} \cdot \mathrm{s}^{-1}$ ) is due to different factors. We suppose that the decisive factor is heterogeneity of the plastic deformation distribution during the forming of the cup at very high strain rates and the deformation is localized in the critical parts of the cup. This can result in a decrease of the total value of plasticity. Changes of the friction between the tool and sheet can have influence, too.

For the service life in the car body the most important properties of pressed steel sheet parts are the resistance against fatigue and corrosion. They are stressed most frequently by alternating forces in bending. In Fig. 4 are plotted the dependences of the fatigue stress oh on the number of cycles to fracture N, for sym-

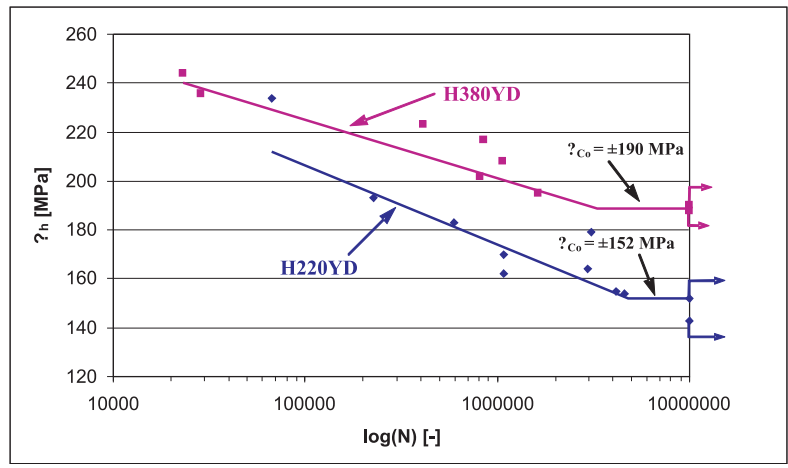

Fig. 4 Wöhler fatigue curves $\sigma h-N$ for tested steel sheets metric cyclic bending of the tested steel sheet. The final fatigue limit and its rate to the UTS are the determined characteristics showing the quality of the resistance to fatigue. The fatigue limit of the steel grade $\mathrm{H} 220 \mathrm{YD}$ in bending was $\sigma_{\mathrm{Co}}= \pm 152 \mathrm{MPa}$ and the rate to UTS was $\sigma_{\mathrm{Co}} / R_{\mathrm{m}}=0.41$. For the steel grade H380LAD it was $\sigma_{\mathrm{Co}}= \pm 190 \mathrm{MPa}$ and $\sigma_{\mathrm{Co}} / R_{\mathrm{m}}=0.37$, respectively. The tested characteristics and the slope of the decreasing Wöhler curve, (Fig. 4) assign both the tested steel grade sheets to ones with a good resistance to fatigue damage.

The increased corrosion resistance of the tested steel sheet is achieved by hot dip zinc coating. Damages of the integrity to the zinc coating layer during forming or service life decrease the corrosion resistance significantly, and can be an initiation spot of damage by fatigue [10, 11]. Macro and microscopic analyses of the tensile test pieces surface layer during tensile testing did neither reveal any damages of the coating nor any loss of cohesion to the steel base. Neither the other tests, the deep drawing Erichsen test and fatigue testing in bending showed damages to the coating. It is documented in Fig. 5 where the fracture surface of the sheet H220YD with the zinc surface layer is shown after cycling with stress equal to the fatigue limit $\sigma_{\mathrm{Co}}$ and life to the limit of $10^{7}$ cycles.

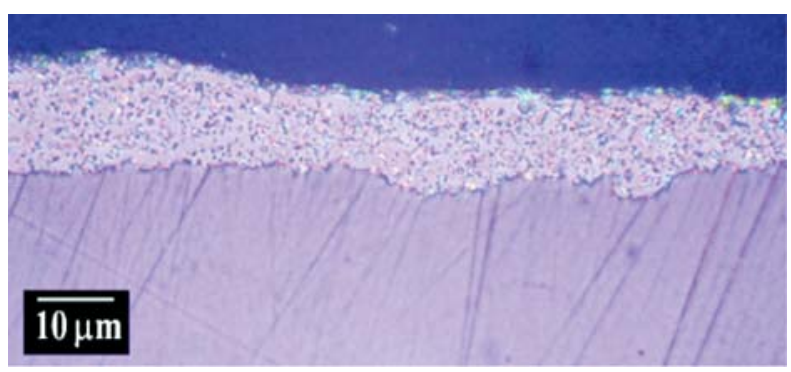

Fig. 5 Fracture of investigated steel H220YD with zinc surface layer after fatigue at $\sigma=152 \mathrm{MPa}, \mathrm{N}=10^{7}$ cycles.

\section{Conclusion}

Deep drawing and fatigue properties of two advanced deep drawing steel grades with yield points 246 and $382 \mathrm{MPa}$ are analyzed in the contribution. The sheets were hot coated with zinc. The influence of the forming tool velocity on the deep drawing Erichsen test results are evaluated (the depth of the drawn cup at cracking).

The experimental results and discussion showed:

- The tested steel grades with increased strength and fatigue properties obtained by grain refinement and precipitation strengthening manifested very promising plasticity properties. The steel grade with high $\mathrm{R}_{\mathrm{e}}=382 \mathrm{MPa}$, though having a lower elongation at tensile testing $\mathrm{A}_{80}=24 \%$, had the Erichsen depth equal to the one for the steel grade with $\mathrm{R}_{\mathrm{e}}=246 \mathrm{MPa}$ and $\mathrm{A}_{80}=32 \%$. A new approach is necessary to evaluate the deep drawing 


\section{COMMNICOIIONS}

properties of these steels if tensile test results are known only $\left(\mathrm{A}_{80}, \mathrm{n}, \mathrm{R}_{\mathrm{e}} / \mathrm{R}_{\mathrm{m}}\right)$

- The increase of the press tool velocity during forming (or at the Erichsen test) up to about $0.2 \mathrm{~m} . \mathrm{s}^{-1}$, which is equal to about $1 \mathrm{~s}^{-1}$ strain rate, results in a slight increase of the deep drawing test result. Exceeding this velocity brings a decrease of deep drawing properties; the decrease is more intense for the steel with a lower yield point.
- The zinc surface layer retained integrity and cohesion to the basic steel up to the final fracture of the tested piece by tensile testing, Erichsen deep drawing tests, and fatigue tests.

\section{Acknowledgement}

This work has been supported by APVV Agency under No. APVV-0326-07

\section{References}

[1] KOCICH, J., TULEJA, S.: Corrosion and Protection of Steels (in Slovak), TU Košice, 1998.

[2] SEVCIKOVA, J.: Surfaces (in Slovak), HF TU Kosice, 2005.

[3] PARILAK, L.: Structural Fundamentals of Mechanical and Fracture Attributes of Materials (in Slovak), Habilitation Thesis, HF TU Kosice, 1998

[4] CIZMAROVA, E. et al.: Metalurgija [Metallurgy], 43/2004, p. 211.

[5] MICHEL, J. et al.: Kovove materialy [Metallic Materials], 37, 1999, 191, (in Slovak).

[6] BURSAK, M. et al.: Metalurgija [Metallurgy], 46/2007, p. 37.

[7] JANOVEC, J., ZIEGELHEM, J.: Increase of Use Properties at Vehicle Sheetmetal (in Czech), In. Technológia '99, STU Bratislava, 1999, p. 319

[8] STABA, J., BURSAK, M.: Metalurgija [Metallurgy], 48/2009, p. 167.

[9] HRIVNAK, A., EVIN, E.: Sheet Compressibility - Compressibility Prediction of Sheet Steel with Advanced Strength Properties (in Slovak), Elfa, Kosice, 2004.

[10] SPISAK, E.: Mathematical Designing and Simulation of Technological Processes for Profiling (in Slovak), TYPO Pres, Kosice 2000.

[11] SPISAK, E. et al.: Production Engineering 1 (in Slovak), Kosice, 2003. 